\title{
A STUDY OF POST LAPAROSCOPIC PORT RELATED COMPLICATIONS
}

\author{
Ateev A. Singh ${ }^{1}$, Pankaj Kumar ${ }^{2}$, Vibhor Mahendru ${ }^{3}$, Mushtaq Ali ${ }^{4}$, Saurabh Rai ${ }^{5}$, Amir Afroz ${ }^{6}$, Anurag Saraswat ${ }^{7}$ \\ 1Junior Resident, Department of General Surgery, Era's Lucknow Medical College and Hospital, Lucknow. \\ 2Professor, Department of General Surgery, Era's Lucknow Medical College and Hospital, Lucknow. \\ ${ }^{3}$ Assistant Professor, Department of General Surgery, Era's Lucknow Medical College and Hospital, Lucknow. \\ ${ }^{4}$ Assistant Professor, Department of General Surgery, Era's Lucknow Medical College and Hospital, Lucknow. \\ ${ }^{5}$ Assistant Professor, Department of General Surgery, Era's Lucknow Medical College and Hospital, Lucknow. \\ 6Junior Resident, Department of General Surgery, Era's Lucknow Medical College and Hospital, Lucknow. \\ ${ }^{7}$ Senior Resident, Department of General Surgery, Era's Lucknow Medical College and Hospital, Lucknow.
}

\section{BACKGROUND}

ABSTRACT

Rapid growths in health care technology have given the surgeon the power of not only treating diseases surgically but also limiting surgical invasiveness. Laparoscopic surgeries are preferred over open surgeries, but laparoscopic surgery is not a panacea to all the problems associated with open surgery. It has its own problems and complications. The present study is planned to assess the post laparoscopic surgery port related complications.

\section{MATERIALS AND METHODS}

The present study was a prospective descriptive study conducted in the Department of General Surgery at Era's Lucknow Medical College and Hospital over a period of eighteen months. A total of 310 patients were included in the study and followed up for a period of three months from the day of surgery.

\section{RESULTS}

Out of 310 patients enrolled in the study, complications were observed only in 8 (2.58\%). Port site infections were present in 6 $(1.94 \%)$ cases while metastasis and hypertrophic scar was observed in $1(0.32 \%)$ case each.

\section{CONCLUSION}

The rate of port-site complication in the present study was found to be $2.58 \%$. The study identified older age, smoking habit and diabetes as the potential risk factors affecting the complication rates.

\section{KEYWORDS}

Laparoscopy, Port Site, Complication, Infection.

HOW TO CITE THIS ARTICLE: Singh AA, Kumar P, Mahendru V, et al. A study of post laparoscopic port related complications. J. Evolution Med. Dent. Sci. 2018;7(08):978-983, DOI: 10.14260/jemds/2018/224

\section{BACKGROUND}

Rapid growths in health care technology have given the surgeon the power of not only treating diseases surgically but also limiting surgical invasiveness. Mouret in 1987 performed the first laparoscopic cholecystectomy changing surgical practice ${ }^{11]}$ and an increase in frequency of laparoscopic abdominal surgery made it common by 1990.[2] Laparoscopic surgeries are preferred over general surgeries because of lower cost, lesser pain and scarring, faster convalescence, lesser hospital stay and overall low cost $[3,4]$ besides these advantages complications are by far very rare.[5] Common complications include infection, incisional hernia, bleeding, etc.

Reusable metallic or disposable plastic trocars are inserted through small skin incisions or ports. These ports form the portal of entry to perform the surgical procedure by means of specially devised instruments and telescope.

'Financial or Other Competing Interest': None.

Submission 26-12-2017, Peer Review 01-02-2018,

Acceptance 08-02-2018, Published 19-02-2018.

Corresponding Author:

Dr. Pankaj Kumar,

B1/109, Sector-G,

Near Navyug Radiance School,

Jankipuram, Lucknow-226021.

E-mail: pkumar6661@gmail.com

DOI: $10.14260 /$ jemds $/ 2018 / 224$

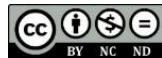

One of the complications associated with laparoscopic surgery is port site infection, which is responsible for significant increase in morbidity, hospital stay and financial loss. However, port site infection is preventable. A vital component of safe effective laparoscopy is the ability to insert, secure, and maintain access ports in an optimal location while avoiding injury to surrounding structures.

The active surveillance for port-site infections in laparoscopic surgery remains a challenge, due to the early discharge and day care setting.[6] In the absence of postdischarge surveillance, it is estimated that a third of all surgical site infections will be missed.[7] The actual incidence of the port-site infections may be much higher than revealed.

Complications of laparoscopy includes abdominal wall bleeding, omental bleeding, abdominal vessel injury, retroperitoneal vessel injury, gastrointestinal perforation, bladder perforation, solid visceral injury, and infection. ${ }^{[8]}$

Although Trocar site hernias (TSH) can occur in wounds of any size, ranging from $2 \mathrm{~mm}$ to $15 \mathrm{~mm}$, most reported cases are in wounds larger than $10 \mathrm{~mm} .{ }^{[9]}$. Nezhat etal. (1997) ${ }^{[10]}$ Reported that the occurrence of TSHs at $5-\mathrm{mm}$ trocar sites was unusual, because the incidence was less than $0.1 \%$. The first trocar site hernia/port site hernia case was described by Fear in 1968[11]. In 1974 Schiff and Naftolin reported two cases of small bowel herniation occurred between the 14th and 21st postoperative days that required laparotomy with small bowel resection. [12] 
Jansen et al. (1997) ${ }^{[13]}$ reported an overall rate of major complications to be approximately 1.4 per 1, 000 procedures following a laparoscopic procedure. However the incidence of port site complications following laparoscopic surgery had been considered to be approximately 21 per 100,000 cases[14] and it has shown a proportional rise with the increase in size of the port site incision and trocar.[15,16]

Sharma et al. (2013) ${ }^{[17]}$ reported potential complications associated with port sites as port site hernias $(0.47 \%)$, port site infections $(1.02 \%)$, discharge from wound $(1.41 \%)$, minor bleeding from port site $(0.70 \%)$, subcutaneous emphysema $(0.58 \%)$, port site metastasis $(0.0 \%)$ in Indian set-up.

The present study is planned to assess the post laparoscopic surgery port related complications.

\section{Aim and Objective}

- To determine the complications associated with ports after laparoscopic surgery.

- To identify the risk factors associated with the common port site complications after a laparoscopic surgery.

\section{MATERIALS AND METHODS}

The present study was a prospective descriptive study conducted in the Department of General Surgery at Era's Lucknow Medical College and Hospital over a period of eighteen months. A total of 310 patients were included in the study and followed up for a period of three months from the day of surgery.

All the patients received pre-operative and post-operative dose of antibiotic as per protocol set by the operating surgeon-

Port Site Complications were studied in Relation to-

- Incidence of complications in a patient.

- $\quad$ Age, Sex and Body Mass Index.

- Diagnosis and Surgical Procedure.

- Port site complication.

- Diabetes mellitus and smoking.

- Common Pathogens involved.

\section{Inclusion Criteria}

All patients undergoing various laparoscopic surgeries.

\section{Exclusion Criteria}

Those cases which were converted to open procedures were excluded from the study.

\section{Statistical Analysis}

Statistical analysis was done using SPSS (Statistical Package for Social Sciences) Version 15.0 Statistical Analysis Software. Chi Square test, Student ' $t$ ' test \& Fisher exact test was used to analyse the data. The values were represented in Number $(\%)$ and Mean \pm SD.

\section{The following Statistical Formulas were used-}

1. Mean.

2. Standard Deviation.

3. Median.

4. Chi square test.

5. Fisher exact test for a cross tabulation.
6. Student ' $t$ ' test.

7. Level of significance: "p" is level of significance.

- $p>0.05$ Not significant.

- $\mathrm{p}<0.05$ Significant.

- $\mathrm{p}<0.01$ Highly significant.

- $\mathrm{p}<0.001$ Very highly significant.

\section{RESULTS}

The present study was conducted in the Department of Surgery, Era's Lucknow Medical College \& Hospital to assess the post laparoscopic surgery port related complications. A total of 310 patients were monitored for port site complications.

Demographic Profile of Patients Enrolled in the Study is given in Tables below

\begin{tabular}{|c|c|c|}
\hline Age Group (Years) & No. of Patients & $\%$ \\
\hline$\leq 20$ & 10 & 3.23 \\
\hline $21-30$ & 82 & 26.45 \\
\hline $31-40$ & 97 & 31.29 \\
\hline $41-50$ & 73 & 23.55 \\
\hline $51-60$ & 36 & 11.61 \\
\hline $61-70$ & 10 & 3.23 \\
\hline $71-80$ & 2 & 0.65 \\
\hline Total & 310 & 100.00 \\
\hline
\end{tabular}

Min-Max (Median): 15-80 (36.00); Mean \pm SD = 38.86 \pm 11.83

\begin{tabular}{|c|c|c|}
\hline Gender & No. of Patients & Percentage \\
\hline Female & 254 & 81.94 \\
\hline Male & 56 & 18.06 \\
\hline \multicolumn{2}{|c|}{ Table 2. Distribution of Study Population according } \\
to Gender \\
\hline
\end{tabular}

\begin{tabular}{|c|c|c|}
\hline Diagnosis & No. of Patients & $\mathbf{\%}$ \\
\hline Appendicitis & 9 & 2.90 \\
\hline Cholelithiasis & 287 & 92.58 \\
\hline Hypersplenism & 1 & 0.32 \\
\hline Left Inguinal Hernia & 2 & 0.65 \\
\hline Paraumbilical Hernia & 1 & 0.32 \\
\hline Right Benign Ovarian Mass & 1 & 0.32 \\
\hline Right Inguinal Hernia & 2 & 0.65 \\
\hline Umbilical Hernia & 7 & 2.26 \\
\hline \multicolumn{2}{|c|}{ Table 3. Distribution of Study Population } \\
according to Diagnosis \\
\hline
\end{tabular}

\begin{tabular}{|c|c|c|}
\hline Laparoscopic Surgery & No. of Patients & $\mathbf{\%}$ \\
\hline Appendectomy & 9 & 2.90 \\
\hline Cholecystectomy & 287 & 92.58 \\
\hline $\begin{array}{c}\text { Laparoscopic Excision of } \\
\text { Ovarian Tumour }\end{array}$ & 1 & 0.32 \\
\hline Laparoscopic Splenectomy & 1 & 0.32 \\
\hline Mesh Hernia Repair & 7 & 2.26 \\
\hline $\begin{array}{c}\text { Transabdominal Pre- } \\
\text { Peritoneal Repair }\end{array}$ & 5 & 1.61 \\
\hline $\begin{array}{c}\text { Table 4. Distribution of Study Population according to } \\
\text { Laparoscopic Surgery }\end{array}$ \\
\hline
\end{tabular}

\begin{tabular}{|c|c|c|}
\hline Complications & No. of Patients & Percentage \\
\hline Port site hematoma & 0 & 0.00 \\
\hline Port site infection & 6 & 1.94 \\
\hline Gaping & 0 & 0.00 \\
\hline
\end{tabular}




\begin{tabular}{|c|c|c|}
\hline Port site hernia & 0 & 0.00 \\
\hline Metastasis & 1 & 0.32 \\
\hline Hypertrophic scar & 1 & 0.32 \\
\hline No complication & 302 & 97.42 \\
\hline Total & 310 & 100.00 \\
\hline
\end{tabular}

Port site complications were not found among $97.42 \%$ of the patients undergoing laparoscopic surgery at our institute. Complications like port site haematoma, Gaping, Port site hernia were not found in any of the patients enrolled in the study. Port site infection was observed in only $6(1.94 \%)$ patients and metastasis and hypertrophic scar was present in $1(0.32 \%)$ of the patients. Complications were observed in only $8(2.58 \%)$ of the patients.

Among 6 cases of infection most common causative organism was Staphylococcus aureus ( $n=4 ; 66.67 \%)$.

\begin{tabular}{|c|c|c|c|c|c|c|}
\hline & \multicolumn{2}{|c|}{$\begin{array}{c}\text { No } \\
\text { Complication } \\
\text { (n=302) }\end{array}$} & $\begin{array}{c}\text { Complications } \\
\text { (n=8) }\end{array}$ & \multicolumn{2}{|c|}{$\begin{array}{c}\text { Total } \\
\text { (N=310) }\end{array}$} \\
\cline { 2 - 7 } & No. & \% & No. & \% & No. & \% \\
\hline Upto 20 & 10 & 3.31 & 0 & 0.00 & 10 & 3.23 \\
\hline $21-30$ & 81 & 26.82 & 1 & 12.50 & 82 & 26.45 \\
\hline $31-40$ & 97 & 32.12 & 0 & 0.00 & 97 & 31.29 \\
\hline $41-50$ & 68 & 22.52 & 5 & 62.50 & 73 & 23.55 \\
\hline $51-60$ & 35 & 11.59 & 1 & 12.50 & 36 & 11.61 \\
\hline $61-70$ & 9 & 2.98 & 1 & 12.50 & 10 & 3.23 \\
\hline $71-80$ & 2 & 0.66 & 0 & 0.00 & 2 & 0.65 \\
\hline
\end{tabular}

Table 6. Association of Age with incidence of Complications

$\chi^{2}=10.978(\mathrm{df}=6) ; \mathrm{p}=0.089$ (Fisher exact test for $<40 \mathrm{yrs}$. vs $>40$ yrs. $\mathrm{p}<0.05$ )

Out of 8 patients who faced complications during the surgery, 1 (12.50\%) was aged 21-30 years, 5 (62.50\%) were aged 41-50 years, 1 (12.50\%) each in age group 51-60 years and 61-70 years. Proportion of patients without complications was higher as compared to with complications was higher in lower age groups i.e. Upto 20 (3.31\% vs. $0.00 \%), 21-30$ years (26.82\% vs. $12.50 \%$ ) and $31-40$ years $(32.12 \%$ vs. $0.00 \%)$ while proportion of patients with complications was higher as compared to without complications among higher age groups $41-50$ (62.50\% vs. $22.52 \%), 51-60$ (12.50\% vs. $11.59 \%), 61-70$ (12.50\% vs. $2.98 \%$ ). Out of 2 patients aged 71-80 years, none faced complications during the surgery. Association of age with incidence of complications in laparoscopic surgeries was not found to be statistically significant ( $\mathrm{p}=0.048$; Fisher's exact test).

\section{Association of Gender with Incidence of Complications} Incidence of complications among female patients $(2.83 \%)$ was found to be higher than that among male patients $(1.82 \%)$. This association was not found to be statistically significant ( $p=1.000$; Fisher exact test).

Association of Diabetes Mellitus and Smoking with incidence of complications

Incidence of complications among diabetic patients (11.54\%) was found to be higher than that among non-diabetic patients
$(0.78 \%)$. This association was found to be statistically significant $(\mathrm{p}<0.001$; Fisher exact test).

Incidence of complications among smokers (15.63\%) was found to be higher than that among non-smoker patients $(1.08 \%)$. This association was found to be statistically significant $(\mathrm{p}<0.001$; Fisher exact test).

\begin{tabular}{|c|c|c|c|c|c|c|}
\hline & \multicolumn{2}{|c|}{$\begin{array}{c}\text { No Compli- } \\
\text { cation (n=302) }\end{array}$} & $\begin{array}{c}\text { Compli- } \\
\text { cations } \\
\text { (n=8) }\end{array}$ & \multicolumn{2}{c|}{$\begin{array}{c}\text { Total } \\
\text { (N=310) }\end{array}$} \\
\cline { 2 - 7 } & No. & $\%$ & No. & $\%$ & No. & $\%$ \\
\hline Appendicitis & 9 & 100.00 & 0 & 0.00 & 9 & 100.00 \\
\hline Cholelithiasis & 279 & 97.21 & 8 & 2.79 & 287 & 100.00 \\
\hline Hypersplenism & 1 & 100.00 & 0 & 0.00 & 1 & 100.00 \\
\hline $\begin{array}{c}\text { Left Inguinal } \\
\text { Hernia }\end{array}$ & 2 & 100.00 & 0 & 0.00 & 2 & 100.00 \\
\hline $\begin{array}{c}\text { Paraumbilical } \\
\text { Hernia }\end{array}$ & 1 & 100.00 & 0 & 0.00 & 1 & 100.00 \\
\hline $\begin{array}{c}\text { Right Benign } \\
\text { Ovarian Mass }\end{array}$ & 1 & 100.00 & 0 & 0.00 & 1 & 100.00 \\
\hline $\begin{array}{c}\text { Right Inguinal } \\
\text { Hernia }\end{array}$ & 2 & 100.00 & 0 & 0.00 & 2 & 100.00 \\
\hline Umbilical Hernia & 7 & 100.00 & 0 & 0.00 & 7 & 100.00 \\
\hline Table 7. Association of Diagnosis with incidence of \\
\hline \multicolumn{3}{|c|}{ Complications } \\
\hline
\end{tabular}

$\chi^{2}=0.658(\mathrm{df}=7) ; \mathrm{p}=0.999$ (Fisher exact test $\left.\mathrm{p}=1.000\right)$

Incidence of complications among cholelithiasis was $2.79 \%$ and in rest of the diagnosis was nil. Majority of patients enrolled in the study were diagnosed as Cholelithiasis ( $\mathrm{n}=287 ; 92.58 \%$ ). Comparing the incidence of complications in cholelithiasis with other diagnosis this difference was not found to be statistically significant $(p=1.000$; Fisher's exact test).

\begin{tabular}{|c|c|c|c|c|c|c|}
\hline \multirow{2}{*}{$\begin{array}{c}\text { Surgical } \\
\text { Procedure }\end{array}$} & $\begin{array}{c}\text { No } \\
\text { complication } \\
(\mathbf{n = 3 0 2})\end{array}$ & $\begin{array}{c}\text { Compli- } \\
\text { cations } \\
\text { (n=8) }\end{array}$ & \multicolumn{2}{c|}{$\begin{array}{c}\text { Total } \\
\text { (N=310) }\end{array}$} \\
\cline { 2 - 7 } & No. & $\%$ & No. & $\%$ & No. & $\%$ \\
\hline Appendectomy & 9 & 2.98 & 0 & 0.00 & 9 & 100.00 \\
\hline Cholecystectomy & 279 & 97.21 & 8 & 2.79 & 287 & 100.00 \\
\hline $\begin{array}{c}\text { Laparoscopic } \\
\text { Excision of Ovarian } \\
\text { Tumour }\end{array}$ & 1 & 0.33 & 0 & 0.00 & 1 & 100.00 \\
\hline $\begin{array}{c}\text { Laparoscopic } \\
\text { Splenectomy }\end{array}$ & 1 & 0.33 & 0 & 0.00 & 1 & 100.00 \\
\hline $\begin{array}{c}\text { Mesh Hernia } \\
\text { Repair }\end{array}$ & 7 & 2.32 & 0 & 0.00 & 7 & 100.00 \\
\hline $\begin{array}{c}\text { Transabdominal } \\
\text { Pre-Peritoneal } \\
\text { Repair }\end{array}$ & 5 & 1.66 & 0 & 0.00 & 5 & 100.00 \\
\hline $\begin{array}{c}\text { Table 8. Association of Surgical Procedure with incidence } \\
\text { of Complications }\end{array}$ \\
\hline
\end{tabular}

$\chi^{2}=0.658(\mathrm{df}=5) ; \mathrm{p}=0.985$ (Fisher exact test $\mathrm{p}=1.000$ )

Incidence of complications among patients undergoing cholecystectomy was $2.79 \%$ which was higher as compared to other procedures $(0.00 \%$ each $)$. Majority of patients enrolled in the study had undergone Cholecystectomy $(n=287 ; 92.58 \%)$. Comparing the incidence of complications among patients underwent cholecystectomy with other 
procedures, this difference was not found to be statistically significant ( $\mathrm{p}=1.000$; Fisher's exact test).

\begin{tabular}{|c|c|c|c|c|c|c|}
\hline \multirow[t]{2}{*}{$\begin{array}{l}\text { Nutritional } \\
\text { Status } \\
\text { (BMI kg/m2) }\end{array}$} & \multicolumn{2}{|c|}{$\begin{array}{c}\text { No } \\
\text { complication } \\
(n=302)\end{array}$} & \multicolumn{2}{|c|}{$\begin{array}{c}\text { Complications } \\
(n=8)\end{array}$} & \multicolumn{2}{|c|}{$\begin{array}{c}\text { Total } \\
(\mathrm{N}=310)\end{array}$} \\
\hline & $\begin{array}{l}\text { No. } \\
\end{array}$ & $\%$ & No. & $\%$ & No. & $\%$ \\
\hline $\begin{array}{c}\text { Underweight } \\
(<18.5)\end{array}$ & 59 & 19.54 & 2 & 25.00 & 61 & 19.68 \\
\hline $\begin{array}{c}\text { Normal } \\
(18.5-24.9)\end{array}$ & 220 & 72.85 & 6 & 75.00 & 226 & 72.90 \\
\hline $\begin{array}{l}\text { Overweight } \\
(25.0-29.9) \\
\end{array}$ & 23 & 7.62 & 0 & 0.00 & 23 & 7.42 \\
\hline
\end{tabular}

$\chi^{2}=0.732(\mathrm{df}=2) ; \mathrm{p}=0.693$ (Fisher exact test $\mathrm{p}=0.828$ )

Proportion of patients with complications during surgery was higher as compared to those without complications among underweight $(25.00 \%$ vs. $19.54 \%)$ and patients with normal nutritional status $(75.00 \%$ vs. $72.85 \%)$ while proportion of patients without complications was higher as compared to patients with complications among overweight ( $7.62 \%$ vs. $0.00 \%)$. This difference was not found to be statistically significant.

\section{DISCUSSION}

Laparoscopic surgery has brought a paradigm shift in the field of surgery by offering minimal invasive surgery, thus optimizing the need for surgical incision and reducing the blood loss during surgery thereby offering a speedier recovery and shorter duration of hospital stay.

However, laparoscopic surgery is not a panacea to all the problems associated with open surgery. It has its own problems and complications. Difficulty in accessibility, visualization and intra-operative vascular damage are some of the complications associated with laparoscopic surgery. Access to targeted organ during laparoscopic surgery is obtained through the help of some small incisions called ports. Different port site complications associated with laparoscopic surgery include pyoderma gangrenosum,[18] metastasis at the port site following laparoscopic oncosurgery,[19] and port site infections (PSIs).[20] These portsite complications associated with laparoscopic surgery, comprise the most intriguing surgical complications that have the capability to revert back the outcome of a surgery. They have great financial consequences too. Owing to these complications the duration of hospital stay is increased which leads to substantial cost escalations.[21] Although evidence has shown that rate of port site complications are relatively lower in elective cases as compared to emergency surgery, ${ }^{[22,23]}$ yet even in highly sophisticated institutions, these complications are a great issue of concern and affect the surgical outcome and patient satisfaction. These complications are strong predictors of treatment success and failure in different types of surgical procedures $[24,25]$ Even in laparoscopic surgery, port site complications, although infrequent can undermine the benefits of the surgery. Although most of these complications are not life threatening, but definitely add a lot to the morbidity, affects the postoperative quality of life, and spoils the aesthesis of the surgery.[26]
With this background the present study was carried out with an aim to determine the complications associated with ports after laparoscopic surgery. For this purpose, a prospective observational study was carried out in which a total of 310 patients undergoing different laparoscopic procedures were enrolled. Age of patients ranged from 15 to 80 years with a mean age of 38.86 years. Majority of patients were females (81.94\%). Cholelithiasis was the most common diagnosis (92.58\%) and cholecystectomy was the most common procedure $(92.58 \%)$. The study population had only $32(10.32 \%)$ smokers and $52(16.77 \%)$ diabetics.

Port-site complications were observed in 8 cases. Thus, incidence of port-site complications in present study was $2.58 \%$. Among different complications, port site infection was seen in $6(1.94 \%)$ cases while $1(0.32 \%)$ case each had metastasis and hypertrophic scar as the port-site complications.

Studies, particularly from India, have not reported portsite hernia as a complication in their series and it has occasionally been reported as a rare entity finding place in literature as case report only.[27] Incidentally, the duration of follow up, absence of obese patients and relatively lesser proportion of cases above 60 years of age (3.9\%) in our study have been responsible for ruling out incisional hernia as the complication in our study. Moreover, in present study improvised techniques to avoid port-site hernia such as use of standard closure (via skin wound), direct visualization closure method and use of suture passer needle were used which itself help in reducing the port site hernia rate.[28] Similar to our study, Singal et al.[28] in their study also showed that use of improvised techniques can minimize the incidence of port-site incisional hernia to $0 \%$.

In present study, apart from port site infection, there was 1 case each of port site metastasis and hypertrophic scar. These complications are relatively lesser and reported in only a few studies. As far as hypertrophic scar is concerned, among different studies reviewed by us, only one study (Adisa et al., 2014) ${ }^{[29]}$ had mentioned it as a complication in their series.

With respect to 1 case $(0.34 \%)$ of port-site metastasis as seen in present study which is also a rare entity and limited only to cases of malignancy treated with laparoscopic method. Karthik et al., 2013; Adisa et al., 2014[29] mentioned about oncologic surgery and reported of a single case of port site metastasis. On reviewing the literature, we found the mention of port site metastasis among exclusive series of oncologic laparoscopic surgeries to be ranging from $0 \%$ to $16 \% \cdot{ }^{[30,31]}$ The occurrence of metastasis at port site is generally reported as case-report only even in series covering laparoscopic oncologic surgery. ${ }^{[31]}$ This makes the occurrence of port-site metastasis in the series covering general laparoscopic surgeries (including some cases of oncologic surgery) to be rarest of rare. The almost negligible proportion of its occurrence in present study $(0.32 \%)$ also signifies the same.

In present study, on evaluating the various possible clinical and demographic determinants of port-site complications, we found the incidence of port-site complications to be significantly higher among cases $>40$ years of age, presence of diabetes and habit of smoking. Interestingly, we did not find an association between BMI and complication rate. Patient's age ${ }^{[32,33]}$ and co-morbidities ${ }^{[34-37]}$ 
are recognized risk factors for port-site complications. The findings of present study endorsed them as potential risk factors for port-site complications. Studies have also mentioned obesity ${ }^{[33,38]}$ as a potential risk factor. However, in present study, we did not have any obese patient and hence are not in a position to comment on this aspect. Although, smoking has been recognized as a factor that increases the risk of surgical site infection [39] in certain specific surgeries, however, it is not recognized as a potential risk factor in most of the studies evaluating port-site complication rate in laparoscopic surgeries.

However, a number of authors consider the port-site complication rate to be independent of predictors like age, sex, BMI, smoking or diabetes while some found the complication rate to be dependent on size of trocar being used or demographic characteristics like age and sex.[38] There are other authors who have found no effect of age, sex, nature of procedure, duration of hospital stay, type of surgery or co-morbidities on the rate of port-site complications. ${ }^{[40]}$ Nevertheless, identification of such risk factors helps in minimization of port-site complications in a particular setting. Awareness of the predisposing factors and modification of techniques can help to reduce the risk.

The findings of present study were interesting and showed that port-site complication rate in our settings was lower than contemporary complication rate in our environment. One of the limitations of study was its shorter follow-up duration, owing to which complications like incisional hernia which generally take a longer time to manifest, could not be encountered.

\section{CONCLUSION}

- $\quad$ Out of 310 patients enrolled in the study complications were observed only in 8 (2.58\%). Port site infections were present in $6(1.94 \%)$ cases while metastasis and hypertrophic scar was observed in $1(0.32 \%)$ case each.

- Among 6 cases of port site infection, causative organism was Staphylococcus aureus in 4 (66.67\%).

- Port related complications were found in significantly higher proportion of patients aged $>40$ years $(5.79 \%)$ as compared to $\leq 40$ years $(0.53 \%)$.

- Port related complications were found in significantly higher proportion of female patients $(2.83 \%)$ as compared to males $(1.82 \%)$

- $\quad$ Port related complications were found in significantly higher proportion of diabetic patients (11.54\%) as compared to non-diabetic patients $(0.78 \%)$

- Port related complications were found in significantly higher proportion of smokers $(15.63 \%)$ as compared to non-smokers $(1.08 \%)$

- No association of diagnosis with port related complications was found.

- No association of surgical procedure with port related complications was found.

- No association of BMI and port related complications were found.

- The limitation of study was shorter duration of follow up.

\section{REFERENCES}

[1] Rosen M, Ponsky J. Minimally invasive surgery. Endoscopy 2001;33(4):358-66.
[2] Duron JJ, Hay JM, Msika S, et al. Prevalence and mechanisms of small intestinal obstruction following laparoscopic abdominal surgery: a retrospective multicentre study. Arch Surg 2000;135(2):208-12.

[3] Squirrel DM, Majeed AW, Troy G, et al. A randomized, prospective, blinded comparison of postoperative pain, metabolic response and perceived health after laparoscopic and small incision cholecystectomy. Surgery 1998;123(5):485-95.

[4] Shukla A, Seth S, Ranjan A. A comparative study between laparoscopic and open cholecystectomy in cases of cholecystitis with cholelithiasis: one year experience in tertiary care center. Int Surg J 2017;4(3):903-7.

[5] Anmad G, Duffy JM, Philips K, et al. Laparoscopic entry techniques. Cochrane Database Syst Rev 2008;(2):CD006583.

[6] Richards C, Edwards J, Culver D, et al. Does using a laparoscopic approach to cholecystectomy decrease the risk of surgical site infection? Ann Surg 2003;237(3):358-62.

[7] Stockley JM, Allen RM, Thomlinson DF, et al. A district general hospital's method of post-operative infection surveillance including post-discharge follow-up, developed over a five-year period. J Hosp Infect 2001;49(1):48-54.

[8] Dugg P, Shivhare P, Singh $\mathrm{H}$, et al. A prospective analysis of port site complications in laparoscopic cholecystectomy. J Minim Invasive Surg Sci 2014;3(2):e17634.

[9] Swank HA, Mulder IM, la Chapelle CF, et al. Systematic review of trocar-site hernia. Br J Surg 2012;99(3):31523.

[10] Nezhat C, Nezhat F, Seidman DS. Incisional hernias after operative laparoscopy. J Laparoendosc Adv Surg Tech A 1997;7:111-5.

[11] Fear RE. Laparoscopy: a valuable aid in gynecologic diagnosis. American Journal of Obstetrics and Gynecology 1968;31(3):297-309.

[12] Schiff I, Naftolin F. Small bowel incarceration after uncomplicated laparoscopy. Obstetrics \& Gynecology 1974;43(5):674-5.

[13] Jansen FW, Kapiteyn K, Trimbos-Kemper T, et al. Complications of laparoscopy a prospective multicentre observational study. Br J Obstet Gynaecol 1997;104:595-600.

[14] Aziz R. Practical manual of operative laparoscopy. New York: Springer-Verlag 1992: p. 1-8.

[15] Kadar N, Reich H, Liu CY, et al. Incisional hernias after major laparoscopic gynecologic procedures. Am J Obstet Gynecol 1993;168(5):1493-5.

[16] Chiu CC, Lee WJ, Wang W, et al. Prevention of trocarwound hernia in laparoscopic bariatric operations. Obes Surg 2006;16(7):913-8.

[17] Sharma D, Patel K, Anchalia MM. Study of cases of complications at port site. International Journal of Science Research (IJSR) 2013;2(12):30-3.

[18] Noblett SE, Woodcock S. Port-site pyoderma gangrenosum - a rare complication of surgical trauma. Ann R Coll Surg Engl 2009;91(8):665-6. 
[19] Wexner SD, Cohen SM. Port site metastases after laparoscopic colorectal surgery for cure of malignancy. Br J Surg 1995;82(3):295-8.

[20] Shindholimath VV, Seenu V, Parshad R, et al. Factors influencing wound infection following laparoscopic cholecystectomy. Trop Gastroenterol 2003;24(2):90-2.

[21] Perencevich EN, Sands KE, Cosgrove SE, et al. Health and economic impact of surgical site infections diagnosed after hospital discharge. Emerging Infectious Diseases 2003;9(2):196-203.

[22] Satyanarayana V, Prashanth HV, Bhandare B, et al. Study of surgical site infections in abdominal surgeries. Journal of Clinical and Diagnostic Research 2011;5(5):935-9.

[23] Maheshwari MK, Pandey S, Bhatnagar AK, et al. A prospective study of surgical site infection in elective and emergency abdominal surgery in CSSH, Meerut. JARBS 2013;5(4):413-8.

[24] Maruo K, Berven SH. Outcome and treatment of postoperative spine surgical site infections: predictors of treatment success and failure. J Orthop Sci 2014;19(3):398-404.

[25] Nichols RL. Preventing surgical site infections. Clinical Medicine and Research 2004;2(2):115-8.

[26] Sasmal PK, Mishra TS, Rath S, et al. Port site infection in laparoscopic surgery: a review of its management. World Journal of Clinical Cases 2015;3(10):864-71.

[27] Rao P, Ghosh K, Sudhan D. Port site hernia: a rare complication of laparoscopy. MJAFI 2008;64(2):187-8.

[28] Singal R, Zamana M, Mittal A, et al. No need of fascia closure to reduce trocar site hernia rate in laparoscopic surgery: a prospective study of 200 nonobese patients. Gastroenterol Res 2016;9(4-5):70-3.

[29] Adisa AO, Alatise OI, Agbakwuru EA, et al. Wound complications following laparoscopic surgery in a Nigerian hospital. Nigerian Journal of Surgery 2014;20(2):92-5.
[30] Freitas T0, Barbosa RM. Prevention of port-site metastasis in gynaecologic malignancies. World J Lap Surg 2013;6(2):77-80.

[31] Kadi N, Isherwood M, Al-Akraa M, et al. Port-Site metastasis after laparoscopic surgery for urological malignancy: forgotten or missed. Article ID 609531, Adv Urology 2012;2012:1-5.

[32] Dulskas A, Lunevičius R, Stanaitis J. A case report of incisional hernia through a $5 \mathrm{~mm}$ lateral port site following laparoscopic cholecystectomy. J Minim Access Surg 2011;7(3):187-9.

[33] Uslu HY, Erkek AB, Cakmak A, et al. Trocar site hernia after laparoscopic cholecystectomy. J Laparoendosc Adv Surg Tech A 2007;17(5):600-3.

[34] Tonouchi H, Ohmori Y, Kobayashi M, et al. Trocar site hernia. Arch Surg 2004;139(11):1248-56.

[35] Mayol J, Garcia-Aguilar J, Ortiz-Oshiro E, et al. Risks of the minimal access approach for laparoscopic surgery: multivariate analysis of morbidity related to umbilical trocar insertion. World J Surg 1997;21:529-33.

[36] Helgstrand F, Rosenberg J, Bisgaard T. Trocar site hernia after laparoscopic surgery: a qualitative systematic review. Hernia 2011;15(2):113-21.

[37] Azurin DJ, Go LS, Arroyo LR, et al. Trocar site herniation following laparoscopic cholecystectomy and the significance of an incidental preexisting umbilical hernia. The Am Surg 1995;61(8):718-20.

[38] Cottam DR, Gorecki PJ, Curvelo M, et al. Preperitoneal herniation into a laparoscopic port site without a fascial defect. Obes Surg 2002;12(1):121-3.

[39] Durand F, Berthelot P, Cazorla C, et al. Smoking is a risk factor of organ/space surgical site infection in orthopaedic surgery with implant materials. International Orthopaedics 2013;37(4):723-7.

[40] Kumar SS, Babu KD, Grace RD, et al. A study of port site infections in laparoscopic surgeries. IOSR Journal of Dental and Medical Sciences (IOSR-JDMS) 2015;14(4) Ver. IV: 20-2. 